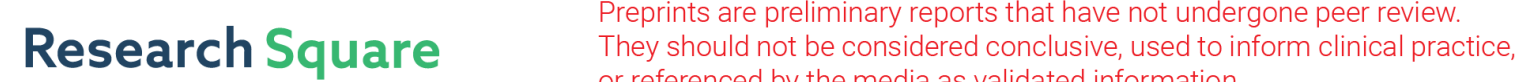 or referenced by the media as validated information.
}

\section{Short-term Outcomes of Totally Laparoscopic Versus Laparoscopy-assisted Total Gastrectomy for Gastric Cancer: a Systematic Review and Meta-analysis}

\section{Fengni Xie}

Xijing Hospital

Zhengyan Li

Xijing Hospital

Jie Chen

Xijing Hospital

Bing Bai

Xijing Hospital

Song Dan

Xijing Hospital

Shuai $X u$

Xijing Hospital

Qingchuan Zhao

Xijing Hospital

Gang Ji ( $\sim$ jigang@fmmu.edu.cn )

Xijing Hospital

\section{Research}

Keywords: Gastric cancer, Laparoscopy, Total gastrectomy, Intracorporeal anastomosis

Posted Date: January 18th, 2021

DOI: https://doi.org/10.21203/rs.3.rs-146984/v1

License: (c) (i) This work is licensed under a Creative Commons Attribution 4.0 International License. Read Full License 


\section{Abstract}

Background Totally laparoscopic total gastrectomy (TLTG) has not been generalized because of its technical difficulty during the procedure of digestive tract reconstruction and lack of short-term results. This meta-analysis aimed to evaluate the feasibility and safety of TLTG for gastric cancer.

Methods A systematic literature search in various databases from January 1994 to November 2020 was performed. Eligible studies in comparing TLTG and laparoscopy-assisted total gastrectomy (LATG) for gastric cancer were included in this meta-analysis. The results were analyzed according to predefined criteria.

Results In the present meta-analysis, the outcomes of 8 non-randomized controlled studies enrolling 1503 patients (819 in the TLTG group and 684 in the LATG group) were pooled. The operation time was significantly shorter in the TLTG group than those in the LATG group $(P<0.01)$. Estimated blood loss was significantly less in TLTG than that in LATG $(P=$ 0.01). The TLTG group was associated with earlier time to first flatus $(P<0.01)$ and oral intake $(P=0.02)$. The pooled analysis showed no significant difference in postoperative hospital stay, postoperative complications, number of retrieved lymph nodes, and the proximal margin between TLTG and LATG groups (all $P \otimes 0.05$ ).

Conclusions TLTG can be a safe and feasible procedure concerning short-term surgical outcomes and complications.

\section{Background}

Laparoscopy-assisted gastrectomy (LAG) has been increasingly performed since it was first reported in 1994 by Kitano et al[1]. Recently, several multicenter randomized controlled trials (RCTs) have reported laparoscopy-assisted distal gastrectomy (LADG) is a safe and feasible surgical procedure for advanced gastric cancer (AGC) in terms of short-term outcomes [2-4]. The incidence of gastric cancer in the upper stomach has been increasing in both Western and Asian countries [5-7]. Several large retrospective studies reported that laparoscopy-assisted total gastrectomy (LATG) is a safe and feasible procedure with acceptable surgical and long-term oncological outcomes for gastric cancer patients [8-11]. During the procedure of $L A G$, resection of the stomach and anastomosis is performed via a small incision in the middleupper abdomen. However, the inclusion of the auxiliary incision in LAG makes it divergent from the minimally invasive treatment concept pursued in minimally invasive surgery. With the accumulation of experience and advancements in laparoscopic surgical instruments, some surgeons in high-volume centers have applied totally laparoscopic distal gastrectomy (TLDG) for gastric cancer [12-16]. A recent meta-analysis demonstrated that TLDG was a technically safe, feasible, and favorable procedure in terms of better cosmesis, less blood loss, and faster recovery compared with LADG[17]. Compared with TLDG, Totally laparoscopic total gastrectomy (TLTG) has not been generalized because of its technical difficulty during the procedure of digestive tract reconstruction and lack of short-term results. A series of reports on TLTG versus LATG for the treatment of gastric cancer have been published in recent years. This study aims to perform a comprehensive evaluation of all the available high-quality published nonrandomized studies to evaluate the feasibility and safety of TLTG for gastric cancer.

\section{Methods}

\section{Literature search}

The work has been reported in line with PRISMA (Preferred Reporting Items for Systematic Reviews and Meta-Analyses) and AMSTAR (Assessing the methodological quality of systematic reviews) Guidelines[18]. A systematic literature was searched from PubMed, MEDLINE, EMBASE, the Cochrane Library, and Web of Science from January 1994 to September 2020 to identify published articles that compared TLTG and LATG. Search terms "gastric carcinoma", "gastric cancer", "laparoscopic", "laparoscopy", "total gastrectomy", "entirely", "totally", "intracorporeal”, and "endocorporeal” were used in 
combination with the Boolean operators AND or OR. The reference lists of articles obtained were also reviewed to find relevant literature. Two authors individually conducted the literature search and cross-checked their search results.

\section{Inclusion and exclusion criteria}

Included criteria for this meta-analysis were as follows: (1) all patients were confirmed gastric cancer; (2) published studies comparing TLTG with LATG for gastric cancer; (3) studies that reported at least one of the following outcomes, including surgical outcome, postoperative complication, or the postoperative recovery outcomes. The excluded criteria were: (1) studies such as reviews, comments, letters, case reports, or cohort studies including fewer than ten patients; (2) studies published in a language other than English.

\section{Data extraction and quality assessment}

Data were extracted independently by two reviewers using predefined standards and cross-checked, and discrepancies were adjudicated by a third reviewer. The following data were extracted from each study: first author, publication year, country, study period, sample size, gender, mean age, level of lymphadenectomy, operation time, anastomotic time, estimated blood loss, time to first flatus, time to first oral intake, postoperative hospital stay, overall complications, anastomosis leakage, anastomosis stricture, number of retrieved lymph nodes, proximal margin. All included studies were methodologically assessed using the Newcastle-Ottawa Scale (NOS), which has been widely used for the assessment of the quality of non-randomized studies in meta-analyses[19]. The high-quality trials should score $\geq 6$ of a maximum score of 9 .

\section{Statistical analysis}

The odds ratio (OR) was used to calculated dichotomous variables. Weighted mean difference (WMD) was used to calculate continuous variables, and both were reported with $95 \%$ confidence intervals (Cls). $R$ statistics were used to quantify the heterogeneity among studies. If data was not significantly heterogeneous $(P>0.05$ or $R<50 \%)$, the pooled effects were calculated using a fixed model. Otherwise, the random-effects analysis would be performed. Data analyses were performed with the Review Manager software (RevMan Version 5.3; Cochrane Collaboration). The results were regarded as statistically significant at two-sided $P<0.05$.

\section{Results}

\section{Study selection}

Finally, 8 non-randomized controlled studies were eligibly included in the pooled analysis [20-27]. The detailed search steps are presented in Fig. 1.

\section{The characteristics and quality of the studies}

Table 1 summarizes the characteristics of the included studies, which were published from 2013 to 2017. These articles are from Japan, Korea, and China. A total of 1503 patients were included in the meta-analysis, among which 819 cases in the TLTG group and 684 in the LATG group. The quality assessment outcomes of non-randomized studies are summarized in Table 2. 
Table 1

Characteristics of included studies

\begin{tabular}{|c|c|c|c|c|c|c|c|c|c|c|}
\hline \multirow[t]{2}{*}{ Study } & \multirow[t]{2}{*}{ Year } & \multirow[t]{2}{*}{ Country } & \multirow{2}{*}{$\begin{array}{l}\text { Study } \\
\text { period }\end{array}$} & \multicolumn{2}{|c|}{ Sample size } & \multicolumn{2}{|c|}{ Gender (M/F) } & \multicolumn{2}{|c|}{ Mean age $(y)$} & \multirow{2}{*}{$\begin{array}{l}\text { Level of } \\
\text { Lymphadenectomy }\end{array}$} \\
\hline & & & & TLTG & LATG & TLTG & LATG & TLTG & LATG & \\
\hline $\begin{array}{l}\text { Jung } \\
\text { et al }\end{array}$ & 2013 & Korea & $\begin{array}{l}2004- \\
2012\end{array}$ & 40 & 47 & $31 / 9$ & $37 / 10$ & 63.4 & 61.2 & D1+/D2 \\
\hline $\begin{array}{l}\text { Ito et } \\
\text { al }\end{array}$ & 2014 & Japan & $\begin{array}{l}2001- \\
2012\end{array}$ & 117 & 46 & NA & NA & NA & NA & $\mathrm{D} 1+/ \mathrm{D} 2$ \\
\hline $\begin{array}{l}\text { Chen } \\
\text { et al }\end{array}$ & 2016 & China & $\begin{array}{l}2006- \\
2015\end{array}$ & 108 & 145 & $73 / 35$ & $98 / 47$ & 59.4 & 57.3 & D2 \\
\hline $\begin{array}{l}\text { Kim } \\
\text { EY et } \\
\text { al }\end{array}$ & 2016 & Korea & $\begin{array}{l}2009- \\
2014\end{array}$ & 27 & 29 & $22 / 5$ & $20 / 9$ & 60.8 & 59.3 & D1+/D2 \\
\hline $\begin{array}{l}\text { Kim } \\
\mathrm{HB} \text { et } \\
\text { al }\end{array}$ & 2016 & Korea & $\begin{array}{l}2013- \\
2015\end{array}$ & 30 & 24 & $16 / 14$ & $14 / 10$ & 51 & 53 & $\mathrm{D} 1+/ \mathrm{D} 2$ \\
\hline $\begin{array}{l}\text { Lu et } \\
\text { al et al }\end{array}$ & 2016 & China & $\begin{array}{l}2011- \\
2014\end{array}$ & 25 & 25 & $22 / 3$ & $21 / 4$ & 59.0 & 58.4 & D1+/D2 \\
\hline $\begin{array}{l}\text { Gong } \\
\text { et al }\end{array}$ & 2017 & China & $\begin{array}{l}2008- \\
2014\end{array}$ & 421 & 266 & $273 / 148$ & $167 / 99$ & 57.8 & 55.7 & D1+/D2 \\
\hline $\begin{array}{l}\text { Huang } \\
\text { et al }\end{array}$ & 2017 & China & $\begin{array}{l}2014- \\
2016\end{array}$ & 51 & 102 & $34 / 17$ & $68 / 34$ & 55.5 & 55.9 & D2 \\
\hline
\end{tabular}

Table 2

Newcastle-Ottawa Scale assessment of non-randomized studies

\begin{tabular}{|c|c|c|c|c|c|c|c|c|c|}
\hline \multirow[t]{2}{*}{ Study } & \multicolumn{4}{|c|}{ Selection } & \multirow{2}{*}{$\begin{array}{l}\text { Comparability } \\
5\end{array}$} & \multicolumn{3}{|c|}{ Outcome } & \multirow[t]{2}{*}{ Total } \\
\hline & 1 & 2 & 3 & 4 & & 6 & 7 & 8 & \\
\hline Jung et al & * & * & * & * & * & * & * & - & 7 \\
\hline Ito et al & * & * & * & * & * & * & - & - & 6 \\
\hline Chen et al & * & * & * & * & $\star \star$ & * & * & - & 8 \\
\hline Kim EY et al & * & * & * & * & * & * & * & - & 7 \\
\hline Kim HB et al & * & * & * & * & * & * & * & - & 7 \\
\hline Lu et al et al & * & * & * & * & $\star \star$ & * & * & - & 8 \\
\hline Gong et al & * & * & * & * & * & * & * & - & 7 \\
\hline Huang et al & * & * & * & * & $\star \star$ & * & * & - & 8 \\
\hline
\end{tabular}




\section{Intraoperative outcomes}

All 8 studies reported operation time [20-27]. The present analysis showed TLTG group had shorter operation time compared to LATG (WMD=-11.41 min; 95\% Cl, - 19.90 to -2.92; $P<0.01$ ) (Fig. 2A). Based on the analysis of our studies reporting anastomotic time, our result revealed that TLTG and LATG groups had similar result (WMD $=2.02 \mathrm{~min} ; 95 \% \mathrm{Cl}$, 5.74 to 9.79; $P=0.61$ ) (Fig. 2B). 6 studies reported estimated blood loss $[21-25,27]$. Estimated blood loss was significantly lower in the TLTG group compared with the LATG group (WMD=-42.35 ml; 95\% Cl, -74.61 to $-10.10 ; P=0.01$ ) (Fig. 2C). All outcomes are summarized in Table 3.

Table 3

Pooled short-term outcomes of meta-analysis

\begin{tabular}{|c|c|c|c|c|c|c|c|}
\hline \multirow[t]{2}{*}{ Outcomes } & \multirow{2}{*}{$\begin{array}{l}\text { No. of } \\
\text { studies }\end{array}$} & \multicolumn{2}{|c|}{ Sample size } & \multirow{2}{*}{$\begin{array}{l}\text { Heterogeneity } \\
(P, R)\end{array}$} & \multirow{2}{*}{$\begin{array}{l}\text { Overall } \\
\text { effect }\end{array}$} & \multirow[t]{2}{*}{$95 \% \mathrm{Cl}$} & \multirow{2}{*}{$\begin{array}{l}P \\
\text { value }\end{array}$} \\
\hline & & TLTG & LATG & & & & \\
\hline Operation time (min) & 8 & 819 & 684 & $0.03,56 \%$ & WMD $=-11.4$ & $\begin{array}{l}-19.90 \text { to } \\
-2.92\end{array}$ & $<0.01$ \\
\hline Anastomotic time(min) & 4 & 200 & 246 & $<0.01,94 \%$ & WMD = 2.02 & -5.74 to 9.79 & 0.61 \\
\hline Estimated blood loss(ml) & 6 & 358 & 371 & $<0.01,78 \%$ & $\begin{array}{l}\text { WMD }= \\
-42.35\end{array}$ & $\begin{array}{l}-74.61 \text { to } \\
-10.10\end{array}$ & 0.01 \\
\hline Time to first flatus (d) & 6 & 672 & 614 & $0.14,40 \%$ & $\begin{array}{l}\text { WMD = } \\
-0.16\end{array}$ & -0.27 to -0.05 & $<0.01$ \\
\hline Time to first oral intake (d) & 7 & 702 & 638 & $0.21,29 \%$ & $\begin{array}{l}\text { WMD }= \\
-0.28\end{array}$ & -0.50 to -0.05 & 0.02 \\
\hline $\begin{array}{l}\text { Postoperative hospital stay } \\
\text { (d) }\end{array}$ & 6 & 281 & 372 & $0.22,29 \%$ & $\begin{array}{l}\text { WMD }= \\
-0.47\end{array}$ & -1.05 to 0.12 & 0.12 \\
\hline Overall complications & 6 & 662 & 591 & $0.49,0 \%$ & $\mathrm{OR}=1.03$ & 0.78 to 1.36 & 0.82 \\
\hline Anastomosis leakage & 7 & 794 & 659 & $0.65,0 \%$ & $\mathrm{OR}=1.58$ & 0.50 to 1.59 & 0.71 \\
\hline Anastomosis stricture & 7 & 794 & 659 & $0.62,0 \%$ & $\mathrm{OR}=0.83$ & 0.38 to 1.83 & 0.65 \\
\hline Retrieved lymph nodes & 6 & 677 & 613 & $0.03,60 \%$ & WMD $=2.22$ & -0.54 to 4.98 & 0.11 \\
\hline Proximal margin $(\mathrm{cm})$ & 6 & 651 & 536 & $<0.01,85 \%$ & $\begin{array}{l}\text { WMD = } \\
-0.50\end{array}$ & -1.18 to 0.17 & 0.14 \\
\hline
\end{tabular}

\section{Postoperative outcome}

Regarding the time to first flatus, TLTG group showed earlier time compared with that in LATG group (WMD = -0.16 d; $95 \% \mathrm{Cl}:-0.27$ to $-0.05 ; P<0.01$ ) (Fig. $3 \mathrm{~A}$ ). The time to first oral intake was 0.28 day earlier for TLTG group with a significant difference $(\mathrm{WMD}=-0.28 \mathrm{~d} ; 95 \% \mathrm{Cl},-0.50$ to $-0.05 ; P=0.02)$ (Fig. 3B). No significant difference between the two groups was observed in terms of postoperative hospital stay (WMD $=-0.47 \mathrm{~d} ; 95 \% \mathrm{Cl}:-1.05$ to $0.12 ; P=0.12)$ (Fig. 3C). Morbidity was mentioned in 6 studies, and there was no significant difference in postoperative morbidity (OR, 1.03; 95\% $\mathrm{Cl}, 0.78$ to $1.36 ; P=0.82$ ) (Fig. 3D). Regarding to anastomotic-related complications, there was no difference between TLTG and LATG groups in terms of anastomotic leakage (OR, $0.90 ; 95 \% \mathrm{Cl}, 0.50$ to $1.59 ; P=0.71$ ) (Fig. 3E) and anastomotic stricture (OR, $0.83 ; 95 \% \mathrm{Cl}, 0.38$ to $1.83 ; P=0.65)$ (Fig. 3F). 
In terms of oncological outcomes, the mean number of retrieved lymph nodes was similar between the two groups (WMD $=2.22 ; 95 \% \mathrm{Cl}$ : -0.54 to $4.98 ; P=0.11$ ) (Fig. 4A). The proximal margin for the TLTG group did not significantly differ from that of the LATG group (WMD $=-0.50 ; 95 \% \mathrm{Cl}:-1.18$ to $0.17 ; P=0.14)$ (Fig. 4B).

\section{Discussion}

Laparoscopy-assisted total gastrectomy has been increasingly performed even though it is always considered technically demanding [28]. In LATG, the digestive tract reconstruction is performed through a 5-7 cm small incision in the middleupper abdomen [29-31]. It has been reported that TLTG has the advantages of less invasive than LATG [32, 33]. However, totally laparoscopic total gastrectomy (TLTG) for gastric cancer has not been generalized because of its technical difficulties and lack of short-term results. So, we performed this meta-analysis to compare the feasibility and safety of TLTG with LATG for gastric cancer.

The postoperative complication is a key index to evaluate the safety and technical feasibility of the surgical procedure. This study demonstrated no significant differences between TLTG and LATG groups in terms of overall postoperative complication rate. The major difference between TLTG and LATG is the methods of digestive tract reconstruction after lymphadenectomy. Therefore, we further analyze the incidence of anastomotic leakage and anastomotic stricture. In this study, the incidence of anastomotic stricture in the TLTG group was ranging from 0 to $10 \%$. Kim et al[34] reported that the use of 45-mm linear staplers during the procedure of side-to-side esophagojejunostomy could create a stoma larger than 30-mm diameter, which therefore reduces anastomotic stricture. Ito et al [21]found there was no significant difference among the TLTG and LATG groups in the incidence of anastomotic stricture. Kim EY et al [23]did not observe anastomotic strictures, even after a long-term follow-up. The present study showed no significant differences between the two groups in terms of anastomosis-related complications. Intracorporeal esophagojejunostomy (IEJ) styles during the procedure of TLTG are various [35-38]. In this study, IEJ styles were liner staple and Orvil ${ }^{\mathrm{TM}}$. However, we could not perform subgroup analysis according to IEJ styles due to the limitation of sample size. Because the IEJ can be difficult, some researchers believe that TLTG was associated with longer operation time [27]. In this meta-analysis, the operation time for TLTG was shorter than LATG. Based on the further analysis of anastomotic time, our result showed that IEJ did not shorten the operation time. However, this result was not consistent among the included studies. In this study, the anastomotic time in the TLTG group was ranging from 18.6 to $47.5 \mathrm{~min}$. Lu et al [25] reported that IEJ can shorten the operation time by 6 min when compared with extracorporeal esophagojejunostomy (EEJ). Conversely, Chen et al [22] found that the TLTG would take a longer time by $15 \mathrm{~min}$ as compared with LATG. As we all know, operation time was always affected by the learning curve. The skillful surgeons are capable of performing the operation safer and faster than unskilled surgeons. Previous studies have demonstrated that 20 to 40 cases are needed to overcome the initial learning curve of TLDG even for surgeons with sufficient experience in LADG $[39,40]$. After completion of the learning for TLDG, the surgeon extended the technique from TLDG to include TLTG. In this study, the included studies did not clearly state the learning stage and experience of surgeons. So, we could not perform subgroup analysis based on different learning stage and surgeon's experience.

This study showed that the estimated blood loss in the TLTG group was significantly lower than that in the LATG group. This might be attributed to TLTG does not need additional mini-laparotomy. Meanwhile, blood vessels in the muscles and mesentery can be more readily identified and are less likely to be transacted during the IEJ [27]. Moreover, the esophageal stump should be pulled out from the abdominal cavity when EEJ is performed. Chen et al [22]stated that the pulling puts great pressure on the esophageal stump and might even cause tearing and bleeding of the spleen envelope. However, we aware that the heterogeneity between studies was high and therefore this result should be interpreted prudently.

In terms of postoperative recovery outcomes, the TLTG group showed the earlier time to first flatus and oral intake. Meanwhile, we also found that the TLTG group was associated with shorter postoperative hospital stay though it failed 
to reach statistically significant. These results suggest that TLTG might a less invasive surgical procedure than LATG.

Theoretically, long-term survival outcomes are a critical measure to evaluate oncological outcomes. In the present metaanalysis, the number of the retrieved lymph nodes and the proximal resection margin is considered as the major indicators of oncological surgical quality due to limited studies included reported the outcomes of long-term follow-up. Chen et al [22] found that the number of harvested lymph nodes of TLTG was more than that of LATG with a marginal difference $(P=0.06)$. In this meta-analysis, our result also revealed a tendency favoring the TLTG group though it failed to reach statistically significant. Logically, TLTG and LATG were similar in the procedure of lymphadenectomy. The marginal difference might because some surgeons perform LATG during their early period. In clinical practice, TLTG was usually performed by surgeons experienced in LATG. Our result showed that the length of the proximal resection margin was similar between the two groups. But this result was in high heterogeneity among the included studies. Gong et al [26] reported a shorter proximal margin in the TLTG group compared with the LATG group. We argued that such a result may relate to the fact that linear staplers are often placed on either side of the resection line and therefore might hinder the evaluation of the surgical margin. Kim et al[24] also found the length of the proximal margin was shorter in TLTG than in the conventional LATG, but the resection margins were free of tumor. Studies conducted by Chen et al and Lu et al demonstrated no significant difference between TLTG and LATG groups. These results suggest that TLTG can also achieve an adequate resection distance.

There are several limitations in the present study. First, all the included studies were retrospective and conducted in single-center from East Asia, which may have a bias in patients selection, surgeons experience, and regional differences, etc. Second, high heterogeneity was observed in some outcomes such as estimated blood loss, operative time, time to first flatus, and postoperative hospital stay. Additionally, limited data were available on long-term survival and quality of life, so we cannot perform further analysis.

\section{Conclusions}

In conclusion, the currently available evidence indicated that TLTG is a safe and feasible procedure compared to LATG concerning short-term surgical outcomes and complications. However, Well-designed multicenter RCTs are warranted to reach more definitive conclusions on this topic.

\section{Abbreviations}

TLTG: Totally laparoscopic total gastrectomy; LATG: laparoscopy-assisted total gastrectomy; LADG: Laparoscopyassisted distal gastrectomy; AGC: Advanced gastric cancer; EEJ: Extracorporeal esophagojejunostomy; ASA: American Society of Anesthesiologists; BMI: Body mass index; T: tumor; N: node; M: metastasis ; TNM: Tumor-node-metastases $\mathbb{S D}$

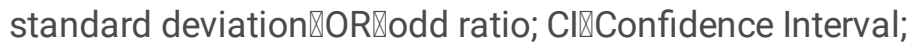

\section{Declarations}

\section{Ethics approval and consent to participate}

This study was approved by the Institutional Review Board of Xijing hospital,

\section{Consent for publication}

Not applicable. 


\section{Availability of data and material}

The datasets analyzed during the current study are available from the corresponding author on reasonable request.

\section{Competing interests}

Not applicable.

\section{Funding}

This study was supported by the National Natural Science Foundation of China (Key Program31670828, 81502401); The National Key Research and Development Program of China(2017YFC1311002ð2017YFC1311004).

\section{Authors' contributions}

Fengni Xie and Gang Ji conceived the study and drafted the manuscript. Fengni Xie, Zhengyan Li and Shuai Xu identified and screened the search findings for potentially eligible studies of the meta-analysis. Bing Bai and Dan Song independently extracted the data using a unified datasheet, and the Qingchuan Zhao was consulted when controversial issues were presented. Jie Chen and Qingchuan Zhao performed the statistical analyses and gave an interpretation of the results. Fengni Xie and Gang Ji revised and supervised the study. All authors read and approved the final manuscript.

\section{Acknowledgements}

Not applicable.

\section{Conflict of interests}

The authors declare that they have no conflict of interests.

\section{Disclosures}

The authors declare that they have no conflict of interest.

\section{References}

1. Kitano S IY, Moriyama M, Sugimachi K (1994) Laparoscopy-assisted Billroth I gastrectomy. Surg Laparosc Endosc $4: 146-148$

2. Park YK, Yoon HM, Kim YW, Park JY, Ryu KW, Lee YJ, Jeong O, Yoon KY, Lee JH, Lee SE, Yu W, Jeong SH, Kim T, Kim S, Nam BH, group C (2017) Laparoscopy-Assisted versus Open D2 Distal Gastrectomy for Advanced Gastric Cancer: Results from a Randomized Phase II Multicenter Clinical Trial (COACT 1001). Annals of surgery 42:S98-S99

3. Hu Y, Huang C, Sun Y, Su X, Cao H, Hu J, Xue Y, Suo J, Tao K, He X, Wei H, Ying M, Hu W, Du X, Chen P, Liu H, Zheng C, Liu F, Yu J, Li Z, Zhao G, Chen X, Wang K, Li P, Xing J, Li G (2016) Morbidity and Mortality of Laparoscopic Versus Open D2 Distal Gastrectomy for Advanced Gastric Cancer: A Randomized Controlled Trial. Journal of clinical oncology : official journal of the American Society of Clinical Oncology 34:1350-1357 
4. Inaki N, Etoh T, Ohyama T, Uchiyama K, Katada N, Koeda K, Yoshida K, Takagane A, Kojima K, Sakuramoto S, Shiraishi N, Kitano S (2015) A Multi-institutional, Prospective, Phase II Feasibility Study of Laparoscopy-Assisted Distal Gastrectomy with D2 Lymph Node Dissection for Locally Advanced Gastric Cancer (JLSSG0901). World journal of surgery 39:2734-2741

5. Kosuga T, Ichikawa D, Komatsu S, Okamoto K, Konishi H, Shiozaki A, Fujiwara H, Otsuji E (2015) Feasibility and Nutritional Benefits of Laparoscopic Proximal Gastrectomy for Early Gastric Cancer in the Upper Stomach. Annals of surgical oncology 22 Suppl 3:S929-935

6. Ahn HS, Lee HJ, Yoo MW, Jeong SH, Park DJ, Kim HH, Kim WH, Lee KU, Yang HK (2011) Changes in clinicopathological features and survival after gastrectomy for gastric cancer over a 20-year period. The British journal of surgery 98:255-260

7. Okabayashi T GT, Kondo H, Inui T, Ono H, Saito D, Yoshida S, Sasako M, Shimoda T. (2000) Early carcinoma of the gastric cardia in Japan: is it different from that in the West? Cancer 89:2555-2559

8. Li Z, Liu Y, Bai B, Yu D, Lian B, Zhao Q (2019) Surgical and Long-Term Survival Outcomes After Laparoscopic and Open Total Gastrectomy for Locally Advanced Gastric Cancer: A Propensity Score-Matched Analysis. World journal of surgery. 43:594-603

9. Lin JX, Huang CM, Zheng CH, Li P, Xie JW, Wang JB, Jun L, Chen QY, Lin M, Tu R (2016) Evaluation of laparoscopic total gastrectomy for advanced gastric cancer: results of a comparison with laparoscopic distal gastrectomy. Surgical endoscopy 30:1988-1998

10. Lee JH, Nam BH, Ryu KW, Ryu SY, Park YK, Kim S, Kim YW (2015) Comparison of outcomes after laparoscopyassisted and open total gastrectomy for early gastric cancer. The British journal of surgery 102:1500-1505

11. Bo T, Peiwu Y, Feng Q, Yongliang Z, Yan S, Yingxue H, Huaxing L (2013) Laparoscopy-Assisted vs. Open Total Gastrectomy for Advanced Gastric Cancer: Long-Term Outcomes and Technical Aspects of a Case-Control Study. Journal of Gastrointestinal Surgery 17:1202-1208

12. Song KY, Park CH, Kang HC, Kim JJ, Park SM, Jun KH, Chin HM, Hur H (2008) Is totally laparoscopic gastrectomy less invasive than laparoscopy-assisted gastrectomy?: prospective, multicenter study. J Gastrointest Surg 12:10151021

13. Kim MG, Kawada H, Kim BS, Kim TH, Kim KC, Yook JH, Kim BS (2011) A totally laparoscopic distal gastrectomy with gastroduodenostomy (TLDG) for improvement of the early surgical outcomes in high BMI patients. Surgical endoscopy 25:1076-1082

14. Kanaji S, Harada H, Nakayama S, Yasuda T, Oshikiri T, Kawasaki K, Yamamoto M, Imanishi T, Nakamura T, Suzuki S, Tanaka K, Fujino Y, Tominaga M, Kakeji Y (2014) Surgical outcomes in the newly introduced phase of intracorporeal anastomosis following laparoscopic distal gastrectomy is safe and feasible compared with established procedures of extracorporeal anastomosis. Surgical endoscopy 28:1250-1255

15. Han WH, Yehuda AB, Kim DH, Yang SG, Eom BW, Yoon HM, Kim YW, Ryu KW (2018) A comparative study of totally laparoscopic distal gastrectomy versus laparoscopic-assisted distal gastrectomy in gastric cancer patients: Shortterm operative outcomes at a high-volume center. Chinese journal of cancer research 30:537-545

16. Chen K, Mou YP, Xu XW, Pan Y, Zhou YC, Cai JQ, Huang CJ (2015) Comparison of short-term surgical outcomes between totally laparoscopic and laparoscopic-assisted distal gastrectomy for gastric cancer: a 10-y single-center experience with meta-analysis. The Journal of surgical research 194:367-374

17. Zhang YX, Wu YJ, Lu GW, Xia MM (2015) Systematic review and meta-analysis of totally laparoscopic versus laparoscopic assisted distal gastrectomy for gastric cancer. World journal of surgical oncology 13:116

18. Moher D, Liberati A, Tetzlaff J, Altman DG, Group P (2009) Preferred reporting items for systematic reviews and meta-analyses: the PRISMA statement. Bmj 339:b2535 
19. Stang A (2010) Critical evaluation of the Newcastle-Ottawa scale for the assessment of the quality of nonrandomized studies in meta-analyses. European journal of epidemiology 25:603-605

20. Jung YJ KD, Lee JH, Kim W. (2013) Safety of intracorporeal circular stapling esophagojejunostomy using trans-orally inserted anvil (OrVil) following laparoscopic total or proximal gastrectomy - comparison with extracorporeal anastomosis. World J Surg Oncol 11:209

21. Ito H, Inoue H, Odaka N, Satodate H, Onimaru M, Ikeda H, Takayanagi D, Nakahara K, Kudo SE (2014) Evaluation of the safety and efficacy of esophagojejunostomy after totally laparoscopic total gastrectomy using a trans-orally inserted anvil: a single-center comparative study. Surgical endoscopy 28:1929-1935

22. Chen K, Pan Y, Cai JQ, Wu D, Yan JF, Chen DW, Yu HM, Wang XF (2016) Totally laparoscopic versus laparoscopicassisted total gastrectomy for upper and middle gastric cancer: a single-unit experience of 253 cases with metaanalysis. World journal of surgical oncology 14:96

23. Kim EY CH, Cho JB, Lee J. (2016) Totally Laparoscopic Total Gastrectomy Versus Laparoscopically Assisted Total Gastrectomy for Gastric Cancer. Anticancer Res 36:1999-2003

24. Kim HB KS, Ha MH, Seo JE, Choi MG, Sohn TS, Bae JM, Kim S, Lee JH. (2016) Comparison of Reduced Port Totally Laparoscopic-assisted Total Gastrectomy (Duet TLTG) and Conventional Laparoscopic-assisted Total Gastrectomy. Surg Laparosc Endosc Percutan Tech 26:e132-e136

25. Lu X, Hu Y, Liu H, Mou T, Deng Z, Wang D, Yu J, Li G (2016) Short-term outcomes of intracorporeal esophagojejunostomy using the transorally inserted anvil versus extracorporeal circular anastomosis during laparoscopic total gastrectomy for gastric cancer: a propensity score matching analysis. The Journal of surgical research 200:435-443

26. Gong CS, Kim BS, Kim HS (2017) Comparison of totally laparoscopic total gastrectomy using an endoscopic linear stapler with laparoscopic-assisted total gastrectomy using a circular stapler in patients with gastric cancer: A singlecenter experience. World journal of gastroenterology 23:8553-8561

27. Huang ZN, Huang CM, Zheng CH, Li P, Xie JW, Wang JB, Lin JX, Lu J, Chen QY, Cao LL, Lin M, Tu RH, Lin JL (2017) Digestive tract reconstruction using isoperistaltic jejunum-later-cut overlap method after totally laparoscopic total gastrectomy for gastric cancer: Short-term outcomes and impact on quality of life. World journal of gastroenterology 23:7129-7138

28. Chen K, Xu XW, Zhang RC, Pan Y, Wu D, Mou YP (2013) Systematic review and meta-analysis of laparoscopyassisted and open total gastrectomy for gastric cancer. World journal of gastroenterology 19:5365-5376

29. Mochiki E, Toyomasu Y, Ogata K, Andoh H, Ohno T, Aihara R, Asao T, Kuwano H (2008) Laparoscopically assisted total gastrectomy with lymph node dissection for upper and middle gastric cancer. Surgical endoscopy 22:19972002

30. Kawamura H, Yokota R, Homma S, Kondo Y (2009) Comparison of Invasiveness Between Laparoscopy-Assisted Total Gastrectomy and Open Total Gastrectomy. World journal of surgery 33:2389-2395

31. Eom BW, Kim YW, Lee SE, Ryu KW, Lee JH, Yoon HM, Cho SJ, Kook MC, Kim SJ (2012) Survival and surgical outcomes after laparoscopy-assisted total gastrectomy for gastric cancer: case-control study. Surgical endoscopy 26:3273-3281

32. Kim HS, Kim MG, Kim BS, Lee IS, Lee S, Yook JH, Kim BS (2013) Comparison of totally laparoscopic total gastrectomy and laparoscopic-assisted total gastrectomy methods for the surgical treatment of early gastric cancer near the gastroesophageal junction. J Laparoendosc Adv Surg Tech A 23:204-210

33. Chen K, He Y, Cai JQ, Pan Y, Wu D, Chen DW, Yan JF, Maher H, Mou YP (2016) Comparing the short-term outcomes of intracorporeal esophagojejunostomy with extracorporeal esophagojejunostomy after laparoscopic total gastrectomy for gastric cancer. BMC surgery 16:13 
34. Kim HS1 KB, Lee S, Lee IS, Yook JH, Kim BS. (2013) Reconstruction of Esophagojejunostomies Using Endoscopic Linear Staplers in Totally Laparoscopic Total Gastrectomy: Report of 139 Cases in a Large-Volume Center. Surg Laparosc Endosc Percutan Tech 23:e209-216

35. Jeong O, Park YK (2009) Intracorporeal circular stapling esophagojejunostomy using the transorally inserted anvil (OrVil) after laparoscopic total gastrectomy. Surgical endoscopy 23:2624-2630

36. Kinoshita T, Oshiro T, Ito K, Shibasaki H, Okazumi S, Katoh R (2010) Intracorporeal circular-stapled esophagojejunostomy using hand-sewn purse-string suture after laparoscopic total gastrectomy. Surgical endoscopy 24:2908-2912

37. Shim JH, Yoo HM, Oh SI, Nam MJ, Jeon HM, Park CH, Song KY (2013) Various types of intracorporeal esophagojejunostomy after laparoscopic total gastrectomy for gastric cancer. Gastric cancer : official journal of the International Gastric Cancer Association and the Japanese Gastric Cancer Association 16:420-427

38. Man IM, Suda K, Kikuchi K, Tanaka T, Furuta S, Nakauchi M, Ishikawa K, Ishida Y, Uyama I (2015) Totally intracorporeal delta-shaped B-I anastomosis following laparoscopic distal gastrectomy using the Tri-Staple reloads on the manual Ultra handle: a prospective cohort study with historical controls. Surgical endoscopy 29:3304-3312

39. Kim HG, Park JH, Jeong SH, Lee YJ, Ha WS, Choi SK, Hong SC, Jung EJ, Ju YT, Jeong CY, Park T (2013) Totally laparoscopic distal gastrectomy after learning curve completion: comparison with laparoscopy-assisted distal gastrectomy. J Gastric Cancer 13:26-33

40. Ahn CW, Hur H, Han SU, Cho YK (2013) Comparison of intracorporeal reconstruction after laparoscopic distal gastrectomy with extracorporeal reconstruction in the view of learning curve. J Gastric Cancer 13:34-43

\section{Figures}



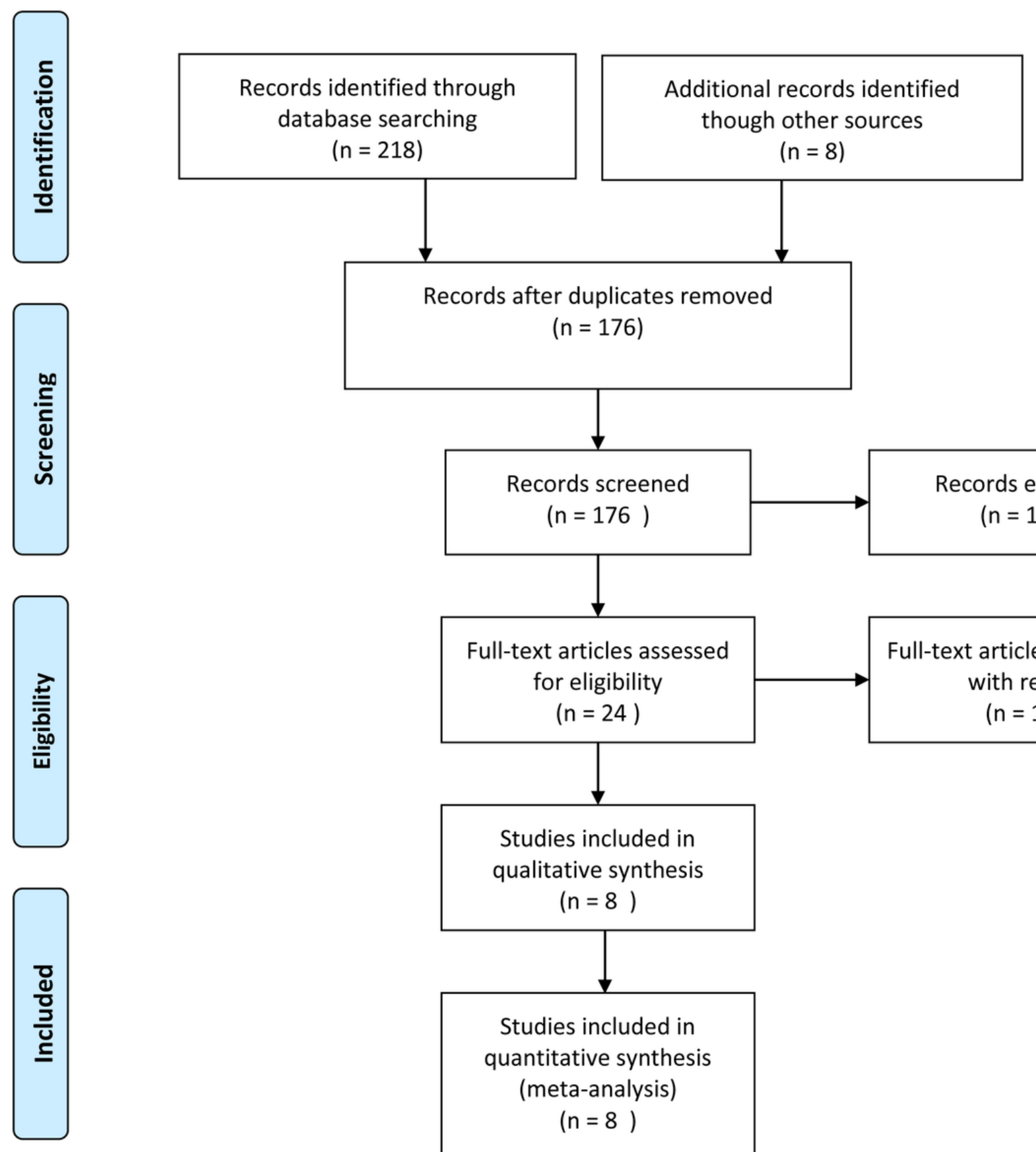

Records after duplicates removed

$$
(n=176)
$$
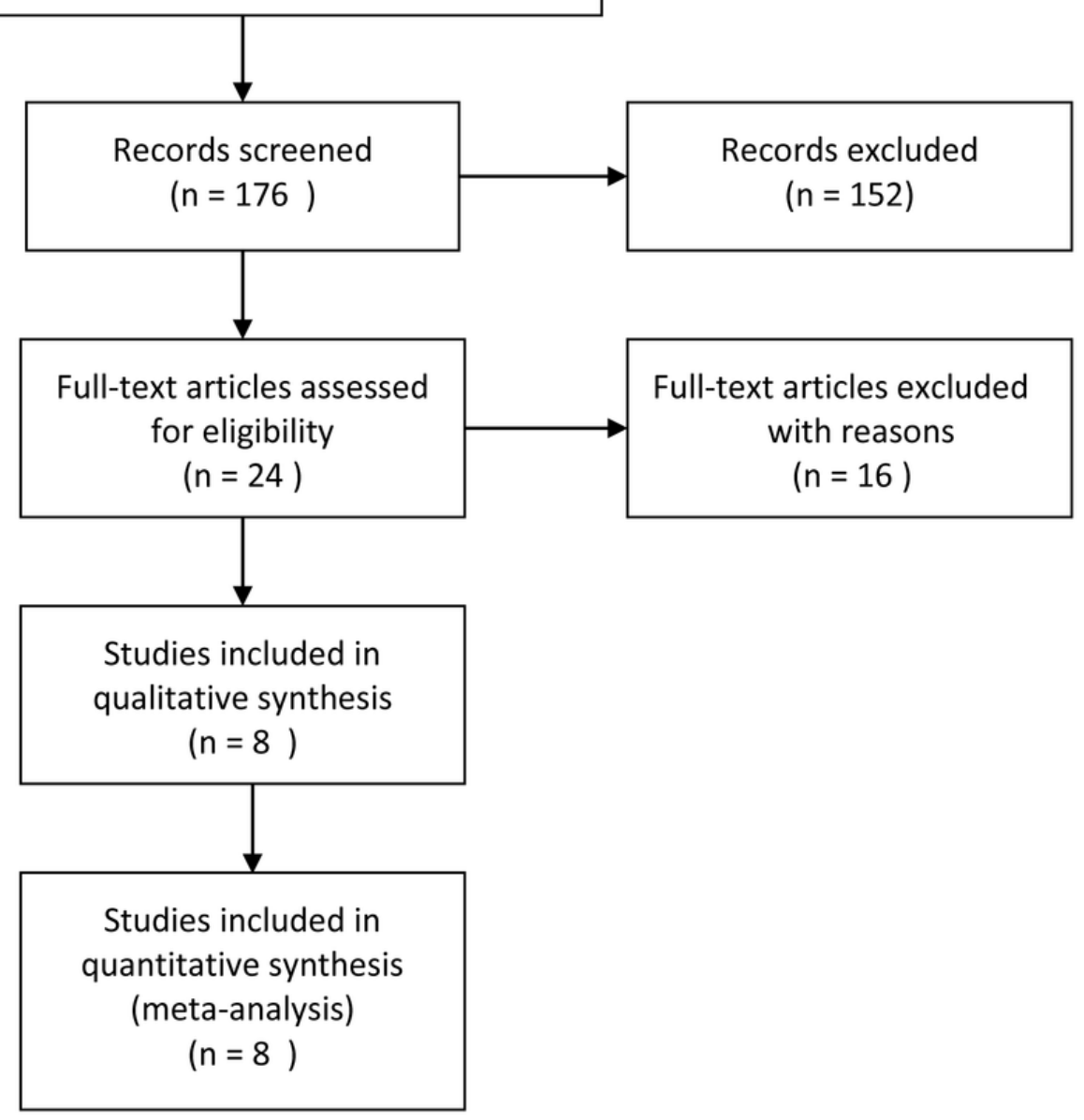

Figure 1

The PRISMA flow diagram of the meta-analysis 
A

\begin{tabular}{|c|c|c|c|c|c|c|c|c|c|c|c|}
\hline Study or Subgroup & ${ }_{\text {Mean }}{ }^{\mathrm{T}}$ & $\begin{array}{l}\text { LTG } \\
\text { SD }\end{array}$ & Total & Mean & $\begin{array}{l}\text { ATG } \\
\text { SD }\end{array}$ & Total & Weight & $\begin{array}{l}\text { Mean Difference } \\
\text { IV. Random, } 95 \% \mathrm{Cl} \text { Year }\end{array}$ & $\begin{array}{r}\text { Mean } \\
\text { IV. Ran }\end{array}$ & $\begin{array}{l}\text { ifference } \\
\text { om. } 95 \% \mathrm{CI}\end{array}$ & \\
\hline Jung et al 2013 & 2.5 & 1.7 & 40 & 2.8 & 1.1 & 47 & $17.8 \%$ & $-0.30[-0.91,0.31] 2013$ & & t & \\
\hline Lu et al et al 2016 & 3.1 & 1.6 & 25 & 2.8 & 1.9 & 25 & $14.6 \%$ & $0.30[-0.67,1.27] 2016$ & & & \\
\hline Kim EY et al 2016 & 2.8 & 1.3 & 27 & 3.2 & 1.7 & 29 & $16.3 \%$ & $-0.40[-1.19,0.39] 2016$ & & & \\
\hline Chen et al 2016 & 4.6 & 1.6 & 108 & 4.3 & 1.7 & 145 & $19.4 \%$ & $0.30[-0.11,0.71] 2016$ & & $=$ & \\
\hline Kim HB et al 2016 & 2.5 & 1.9 & 30 & 4.5 & 2.4 & 24 & $12.8 \%$ & $-2.00[-3.18,-0.82] 2016$ & & & \\
\hline Gong et al 2017 & 2.7 & 2.6 & 421 & 3.9 & 3.1 & 266 & $19.2 \%$ & $-1.20[-1.65,-0.75] 2017$ & & & \\
\hline Total $(95 \% \mathrm{Cl})$ & & & 651 & & & 536 & $100.0 \%$ & $-0.50[-1.18,0.17]$ & & & \\
\hline \multicolumn{9}{|c|}{$\begin{array}{l}\text { Heterogeneity: } \text { Tau }^{2}=0.56 ; \mathrm{Chi}^{2}=32.69, \mathrm{df}=5(P<0.00001) ; \mathrm{I}^{2}=85 \% \\
\text { Test for overall effect: } Z=1.46(P=0.14)\end{array}$} & $\begin{array}{c}-2 \\
\text { Favours TLT }\end{array}$ & Favours L & $\begin{array}{l}2 \\
\text { LATG }\end{array}$ \\
\hline
\end{tabular}

$\mathrm{B}$

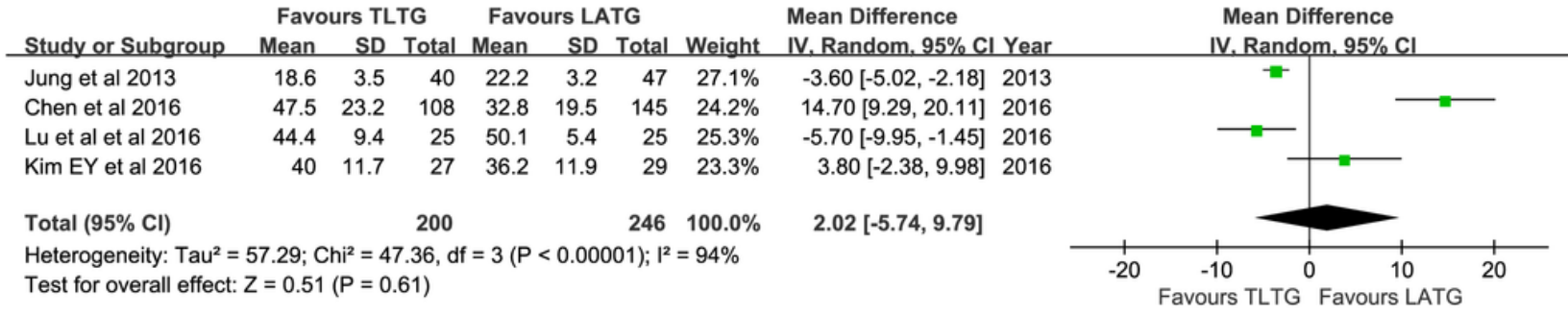

$\mathrm{C}$

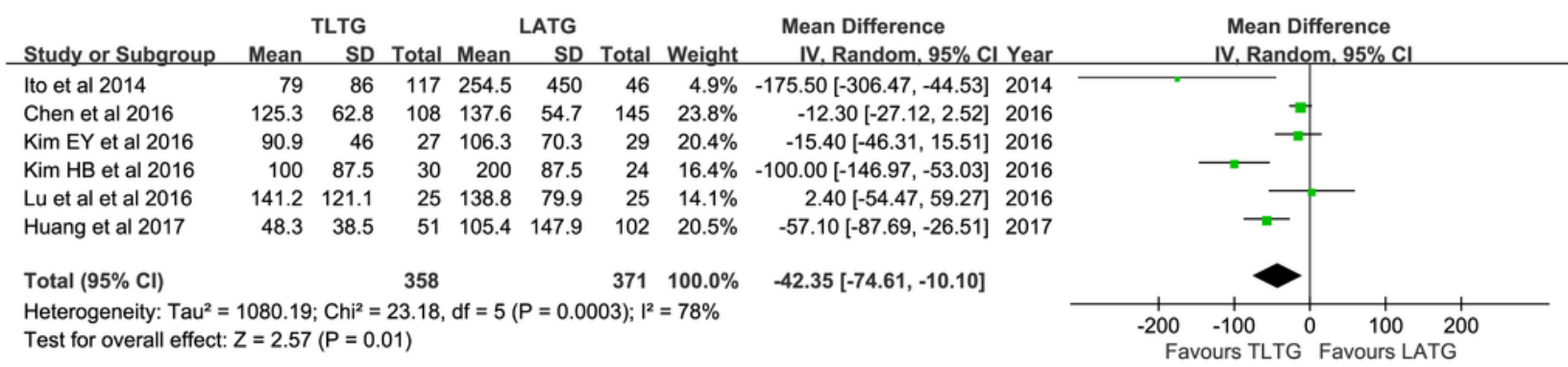

Figure 2

Forest plot of intraoperative outcomes. A operation time; B anastomotic time; C Estimated blood loss. 
A

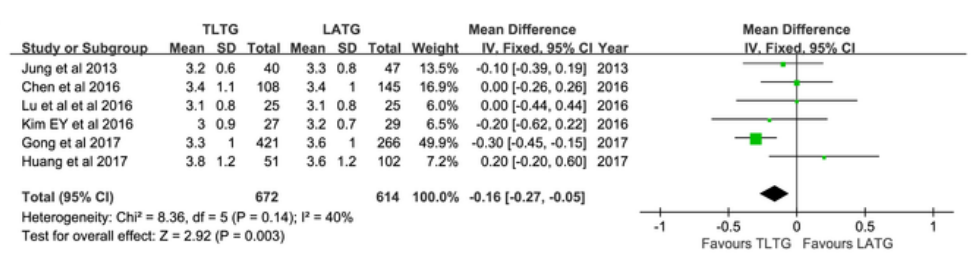

B

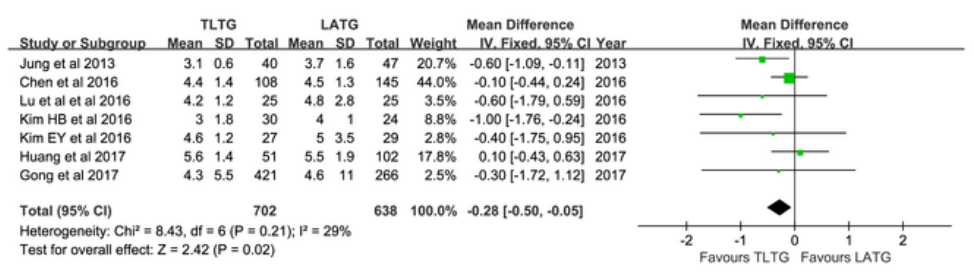

$\mathrm{C}$

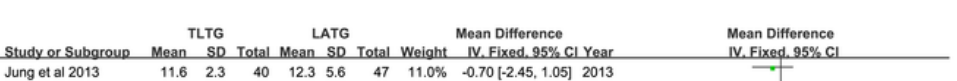
Study or Subgroup Mean SD Total Mean SD Total Weight IV. Fixed. 95\% CI Year \begin{tabular}{lrrrrrrrrr}
\hline Jung et al 2013 & 11.6 & 2.3 & 40 & 12.3 & 5.6 & 47 & $11.0 \%$ & $-0.70[-2.45,1.05]$ & 2013 \\
Lu et al et al 2016 & 8.8 & 5 & 25 & 9.6 & 3.9 & 25 & $5.5 \%$ & $-0.80[-329.1 .69]$ & 2016
\end{tabular}

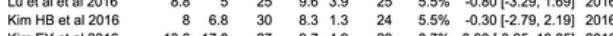
$\begin{array}{lllllllllll}\text { Kim EY et al } 2016 & 13.6 & 17.8 & 27 & 9.7 & 4.9 & 29 & 0.7 \% & 3.90 & {[-3.05,10.85)} & 2016\end{array}$

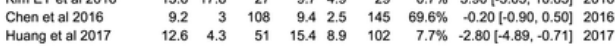

Total $(95 \% \mathrm{Cl}) \quad 281 \quad 372 \quad 100.0 \%-0.47[-1.05,0.12]$ Heterogeneity: Chi $=7.01$, df $=5(P=0.22): i^{2}=29 \%$

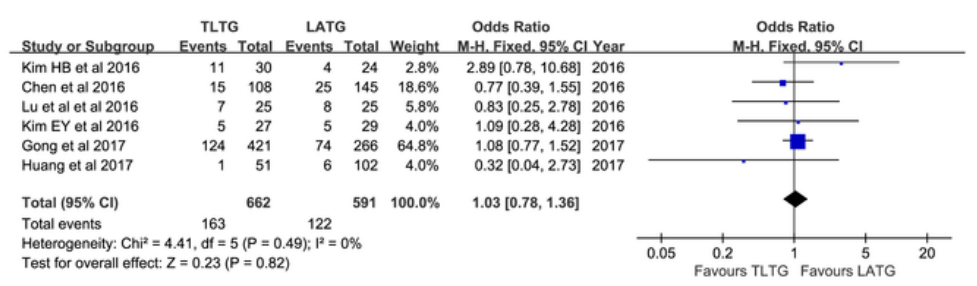

$\mathrm{E}$

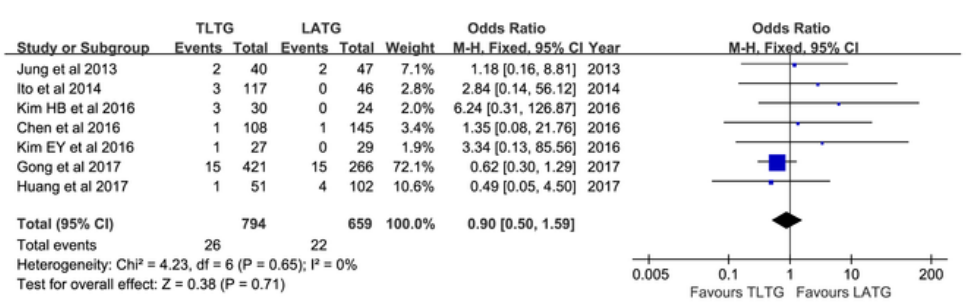

$\mathrm{F}$

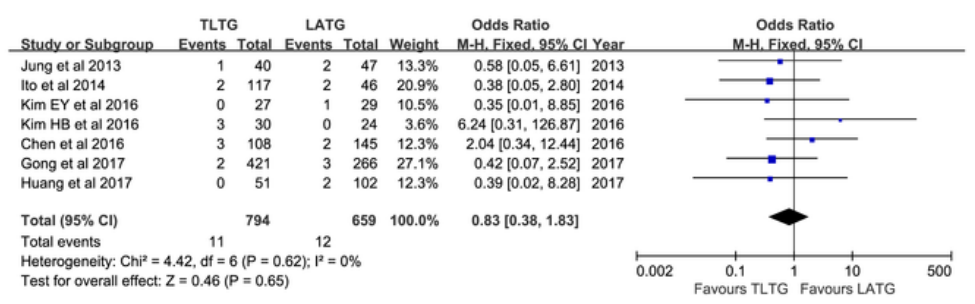

Figure 3

Forest plot of postoperative outcome. A time to first flatus; B time to first oral intake; C postoperative hospital stay; D postoperative morbidity; $\mathrm{E}$ anastomotic leakage; $\mathrm{F}$ anastomotic stricture. 
A

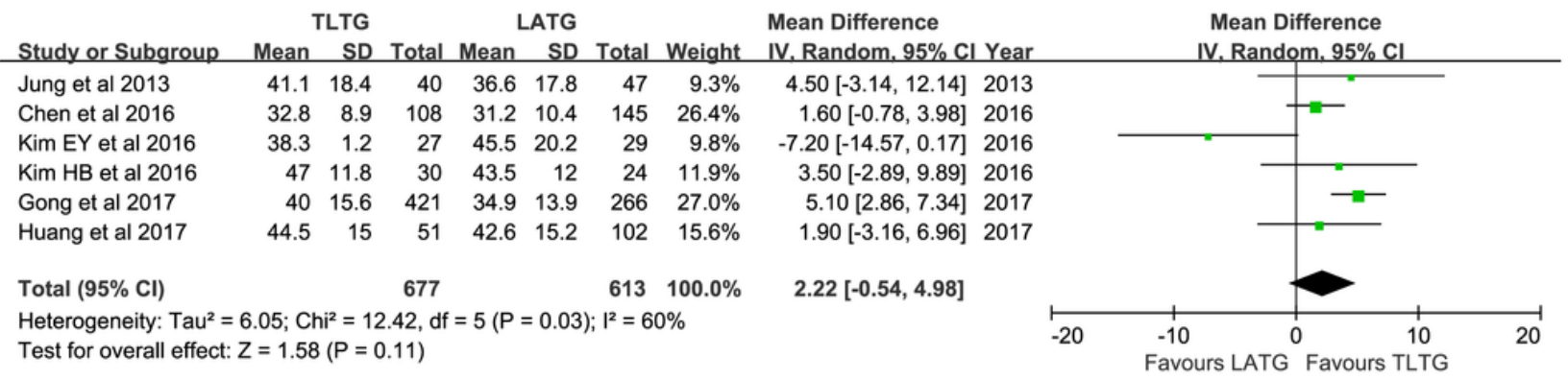

B

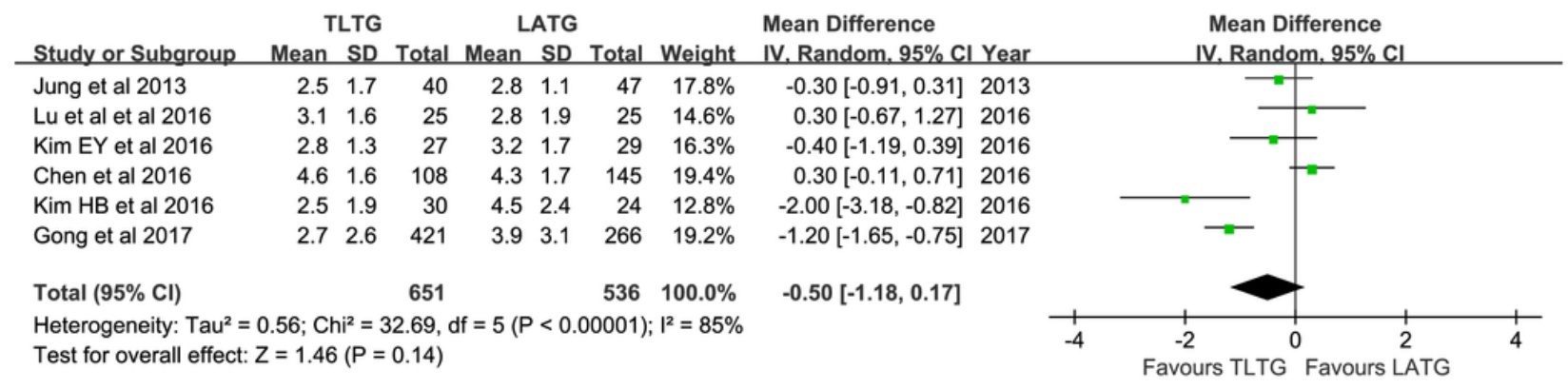

\section{Figure 4}

Forest plot of oncological outcomes. A number of retrieved lymph nodes; B proximal margin. 